\title{
Discussion on Teaching Content and Teaching Method of Health Qigong Course in Colleges and Universities
}

\author{
Quanling He \\ Institute of physical education, Xinxiang University, Henan 453003, China
}

\begin{abstract}
Body-building qigong contains rich philosophy and profound cultural heritage is conducive to the promotion of Chinese traditional culture in college students, the teaching content and teaching method of fitness qigong course is the key to improve the teaching effect.
\end{abstract}

Keywords: Universities; Health qigong; Teaching content; Teaching method

\section{高校健身气功课程的教学内容及教学方法探讨}

\author{
何全玲 \\ (新乡学院 体育学院, 河南省 新乡市 453003)
}

摘要: 健身气功蕴含着丰富的哲理和深厚的文化底蕴, 有利于在大学生群体弘扬中国传统文化, 我国高校顺应时代发展 潮流, 设置健身气功体育课程, 研究探讨健身气功课程的教学内容和教学方法, 是提高教学效果的关键。

关键词: 高校; 健身气功; 教学内容; 教学方法

引言

健身气功是以追求人、自然、社会三者和谐发展为目的民族传统体育项目, 越来越多的高校开设健身 气功课程, 既有利于防治现代生活给学生带来的亚健康问题, 又是弘扬中华民族传统文化的载体。如何科 学设置健身气功课程的教学内容和教学方法, 直接影响健身气功课程在高校的开展效果。

\section{1 健身气功在高校的开展情况}

健身气功是中华民族独有的民族传统体育项目, 是中华民族优秀的文化遗产, 有着深厚的文化底蕴。 《体育发展 “十三五” 规划》和《全民健身计划（2016-2020 年)》提出 “开展全民健身活动, 提供丰富 多彩的活动供给, 扶持推广武术、太极拳、健身气功等民族、民俗、民间传统和乡村农味、农趣运动项目”, 已经明确把健身气功列为重点发展的全民健身项目。[1] 目前已有 300 来所高校开展了健身气功教学活动, “进高校” 数量呈现稳步增长的趋势。高校是中华传统文化继承的载体, 精心培育, 重点推广健身气功这 一具有深厚传统文化基因的体育项目, 是时代的号召, 也是响应 “伟大民族复兴梦” 的积极举措。高校也 是传播知识与文化的摇篮, 良好的课程教学内容和科学的教学方法对健身气功的发展起到至关重要作用。

\section{2 健身气功课程教学内容及教学方法现状}

目前开设有健身气功的高校大多只安排 2-4 学时的理论知识讲授, 而在实际教学过程中, 理论知识讲 授内容又少之又少, 而且没有穿插在功法教学过程中, 大部分理论部分安排在开课第一周或考前一两周, 从而造成理论与实践严重脱节的现象。有些高校在健身气功课程设置上采用理论课和实践课相结合的授课 模式, 但理论课占健身气功课程总课时的比例却是很低, 不足 $30 \%$, 而且实际情况往往极少安排理论课学 习。课程形式单一, 上课内容多为技术动作, 不能满足健身气功的课程目标, 不能满足大学生多元化的需 求。

健身气功课程的教学多沿用传统技术教学和民族传统体育项目练功的方法, 但就健身气功自身的特点 
和课程目标来看, 常规教学远远不能满足课程教学的需求。

\section{3 改革健身气功课程教学方法, 确定科学合理的教学内容的必要性}

健身气功不仅是传统的体育项目, 更是具有深厚文化底蕴、承载了中华民族优秀传统文化的代表。健 身气功富有悠久的历史, 是以自身形体活动、呼吸吐纳、心理调节相结合为主要运动形式的民族传统体育 项目。[2]在多元化文化的浪潮中, 涌现出很多国外体育文化的热潮, 比如 “瑜伽热”, 它们冲击着我国的 体育运动事业。而具有中国传统文化的健身气功在我国体育运动事业的发展中却相对受到了冷落。高校体 育课程科学地开设健身气功, 不仅有助于大学生树立终身体育意识, 而且还能弘扬我国传统文化知识。作 为具有先进创造能力和丰厚知识的大学生, 有义务将健身气功的民族传统文化发扬光大。健身气功课程的 具体教学内容往往忽视健身气功与中医养生文化之间的内在联系。探讨高校健身气功课程的教学内容及教 学方法, 直接关系到健身气功课程的发展和健身气功的传播。

\section{4 以健身和养生为基础的健身气功课程的教学内容}

目前, 健身气功教学的内容主要是围绕国家体育总局编创和推广的四种健身气功展开的。合理的课程 内容安排应符合知识论的规律, 课程的内容能够反映学科的主要知识, 主要的方法论及时代发展的要求与 前沿。

\section{1 健身气功的健身机理}

加强健身气功生理学基础和心理学的理论教学, 加强中医养生与健身气功间的内在联系, 将中医养生 的整体观、阴阳学说、五行学说、经络学说、脏腑学说、辨证论治应用在健身气功的理论教学里。[3]让 学生在健身、养心的同时培养对传统文化的认识和理解。

从运动养生学角度来看, 运动养生要精神悠闲、形体运动, 健身气功注重形神共养、内外兼修。现代 科学研究表明, 坚持习练健身气功能够改善体质状况, 增进心理健康, 改善血液生化指标, 增强系统功能, 益智增智。从中医养生角度来看, 气功健身在于通过阴阳平衡规律, 协调脏腑阴阳、气血的偏盛偏衰, 促 进人体朝着阴平阳秘的健康状态发展; 通过五行生克制化规律, 协调脏腑相互间任何一脏因失去平衡而发 生疾病或衰弱; 通过疏通经络各脏腑、四肢百骸和经、气、血、的、津液的充养, 从而优化人体的生命活 动。从现代医学角度看, 习练健身气功可以调节神经体液系统, 激发人体的自愈能力, 从而达到祛病强身 的作用。从心理健康角度看, 习练健身气功可以通过主动的自我心理活动调整机体的生理功能活动, 进而 改善躯体健康。

\section{2 健身气功的功法知识}

我国传统医学理论认为, 人的身体和精神的协调统一是健康的重要标志, 也是强身健体追求的目标。 健身气功理论将人的身体和精神归纳为 “形” 和 “神”, 而将 “气” 看做是联系 “形” 和 “神” 的纽带, 从而使三者形成一个有机的整体。正所谓: “形者, 生之舍也; 气者, 生之充也; 神者, 生之制也。健身 气功以调身、调息、调心来分别对应人的 “形” “气” “神”，从而使 “三调” 成为健身气功锻炼的基本要 素。[4]

\section{3 练习健身气功的相关知识}

健身气功课程不同于其他技术课, 它有很多需要讲授和讲解的内容, 比如气功理论、功法特点、健身 机理、注意事项要在练功前向学生讲授, 而功法动作、基本要领、某些概念、功法作用等等要贯穿在功法 
练习中进行讲解。

\section{5 健身气功课程教学方法}

在实际教学过程中, 要紧紧围绕 “三调”, 分阶段分层次地进行教学。主要分为三个教学阶段: 基础 教学阶段、巩固提高阶段和全面掌握阶段。在基础教学阶段学生初步掌握动作套路和运行路线, 此阶段主 要任务是功法操练; 巩固提高阶段则要求学生基本掌握功法套路, 教师可在此阶段纠正错误, 并提醒学生 配合动作调息, 学生可在口令引导下通过功法演练, 熟练功法技术动作, 继而能独立演练; 到了全面掌握 阶段就要完善细节, 规范动作, 这个阶段要求做到形、神、意合一, 身心内外兼修, 此阶段学生可利用提 示音乐和功法演练音乐进行自如演练。单就 “呼吸” 来讲, 初级阶段应自然呼吸, 以学动作为主, 熟练后 进入中级阶段, 再结合动作的升降、开合逐渐呼吸。习健身气功时, “意” 很重要, 健身气功的 “用意” 的基本方式是 “内视”、“假想”, “用意” 贯穿始终, 但在学练的不同阶段, “用意” 的层次有所不同, 初 学者, 强调 “重形不重意”, 即把思想意识集中到功法动作上来熟能生巧之后再逐渐体会内, 进入 “形意 并重” 阶段, 即一方面注意动作的规范和标准, 一方面探求健身气功的内在实质和精髓, 加上了意念的要 求。经过长期的习练, 动作达到自动化阶段, 就会自然进入 “重意不重形” 阶段, “无形无意” 是练习的 最高层次。 [5]

\section{6 结论}

高校健身气功课程具有健身养心和培养对传统文化的认识等多方面的作用, 所以在高校课程设置上需 要立体化的设置, 课内、课外有机融合, 教师评价、学生互评相结合, 普训、竞赛相结合, 健身与挖掘项 目的传统文化内涵相结合, 从而形成健身气功完整的课程体系, 建立科学的教学理念和方法, 引导学生养 成具有民族传统特色的体育锻炼习惯。没有实践经验的理论是无根浮萍, 而没有理论指导的实践是盲人摸 象, 理论实践结合实现健身气功课程教学的成功。

\section{参考文献:}

[1] 秦立凯．高校健身气功 MOOC 教学的必要性分析 [J]. 中华武术·研究，2016, 11:77-81,76.

[2] 李晓智. 高校健身气功课程立体构架模式的探索一一以东南大学健身气功课程开展为例 [J]. 体育世界 (学术) 2016, $10: 138,133$

[3] 余忠舜. 基于弘扬中医养生文化的健身气功教学研究 [J]. 当代体育科技, 2015, 5 (27) :204-205.

[4] 国家体育总局健身气功管理中心编. 健身气功知识荟萃 $[\mathrm{R}]$. 第一版. 北京: 人民体育出版社, 2011 年.

[5] 国家体育总局健身气功管理中心编. 健身气功 [G]. 第一版. 北京: 人民体育出版社, 2010 年.

\section{References}

[1] Qin Likai: "Analysis on the necessity of body-building qigong teaching in colleges and universities" [J]. Chinese Martial Arts• study, (2016) No.11: p.77-81, 76(in Chinese)

[2] Li Xiaozhi: "On the three-dimensional structure model of body-building qigong course in colleges - taking the health qigong course in southeast university as an example" [J]. Sports world (academic), (2016) No.10: p. 138,133 (in Chinese)

[3] Yu Zhongshun: "Teaching research of fitness qigong based on promoting health culture of traditional Chinese medicine" [J]. Contemporary Sports Technology, Vol. 27(2015) No.5: 204-205 (in Chinese)

[4] National sports general administration of fitness qigong management center: Knowledge gathering of fitness qigong (ISBN; Beijing; Peoples Sports Publishing House)

[5] National sports general administration of fitness qigong management center: Health Qigong (ISBN; Beijing; Peoples Sports Publishing House) 